\title{
Identification of An Antigenic and Potential Diagnostic Marker of Leishmania donovani Infection by Immunoblot Assay
}

\author{
Krishna D. Manandhar \\ Central Department of Biotechnology \\ Tribhuvan University, Kirtipur, Kathmandu \\ e-mail: krishna.manandhar@gmail.com
}

\begin{abstract}
Leishmania donovani parasites from a sodium antimony gluconate (SAG) refractory patients of endemic region were cultured for extraction of crude soluble antigen and performed Western blot with sera from 138 subjects of different groups for diagnosis of Kala azar. The pretreated patients, however, frequently showed 18 bands of different molecular weight, the 85, 74, 63, 31, and $28 \mathrm{kDa}$ were the major proteins against which more than 75\% patients developed antibodies. The $74 \mathrm{kDa}$ protein fraction band, which was consistently present in all the pretreated patients(n=35), completely waned out or found in state of virtually absent gloomy band in the six-month follow up patients $(n=24)$. Furthermore, the band was absent in $91 \%$ of healthy controls from endemic population( $(n=33)$ and was absolutely absent in non-endemic $(n=13)$ and other diseased(n=19) subjects. Although the band was present in $86 \%$ of Day 31 subjects(n=14), the average integrated density value $(5110 \pm 634)$ of the paired samples was significantly less (p value, $<0.0001)$ than that of Day $0(11385 \pm 1230)$. The nature of the antigen showed its diagnostic and prognostic importance along with marker for kinetic recovery. Sensitivity and specificity of the protein were absolute in patients and non-endemic population, however, sensitivity was $94 \%$ in endemic population. Moreover, it did not show cross-reactivity to different disease groups. Hence, it could be a good diagnostic tool for Kala-azar disease.
\end{abstract}

Key words: antigenic fraction, diagnosis, immunoblot, Kala-azar, leishmaniasis, SDS-PAGE

\section{Introduction}

Visceral leishmaniasis(VL) is caused by Leishmania donovani, which comes under an important disease as it causes absolute death if untreated. It accounts for 75,000 deaths per year (Ashford et al. 1992, Desjeux 2004) and is clearly a poverty-related disease characterized by prolong fever (often with chills and rigors), splenomegaly, hypergammaglobinaemia, hypoalbuminemia, weight loss, lymphadenopathy and pancytopenia (Berman 1997). It has been a major problem in the affected regions of the Indian subcontinents (India, Nepal and Bangladesh), Brazil and Sudan with $90 \%$ of the total outbreak for which high priority is given by their respective governments (Yao et al. 2007). In Nepal, 13 districts from southeastern Terai region are endemic zone for VL and more than 6 million people are at risk and average toll rate for it is around 1341 cases annually (Pun et al. 2011). The real figure of its impact is beyond the official data as many peoples in rural areas are dying without proper diagnosis before they come for treatment.

L. donovani composed of many soluble protein components of glycoproproteins and lipoproteins make the parasites antigenically complex albeit only a limited number of antigens evoke protective host immunological responses (Manuel \& Behin 1987). The polyclonal activation of host immune response against putative leishmanial proteins lead to enormous production of IgG, the major class of antibodies present in the sera of Kala-azar patients (Ghose et al. 1980). Although the life cycle of the parasites involve an extracellular motile promastigote in sandfly and an intracellular non-motile amastigote within the 
mononuclear phagocytes of vertebrate host, there are many immunogenic proteins, which are common in both stages (Handman et al. 1984). These proteins have been shown to play important roles in parasite virulence both in vector and the mammalian host and are very useful clinically (Mengeling et al. 1997, Ilg et al. 1998, Ilg et al. 1999, Piani et al. 1999, Stierhof et al. 1999). Exploitation of these antigens would thus be the better means for diagnosis.

For the study of antigens and selection of appropriate diagnostic marker, Western blotting (Immunoblotting) is being used as an effective and simple technique. Immunoblots from SDS-PAGE comprehensively documents the antigenicity of the parasites and the range of the specificities of antibody responses against these parasites (Forgber et al. 2006). The usefulness and high sensitivity of immunoblotting methods and its superiority over serodiagnostic methods like IFA, ELISA for diagnostic purpose have been well established (Mary et al.1992, Albertini et al.1993, Badaro et al. 1996, Salotra et al. 1999). Reports on a number of Leishmania antigens of molecular weight ranging from $14-76 \mathrm{kDa}$ and a few higher molecular weight antigens have been reported as diagnostic marker for symptomatic as well as asymptomatic VL (Tiwari et al. 1995, Da Costa et al. 1996, Aisa et al.1998, Fernandez-Perez et al. 1999, Rami et al. 2005).

This part of the study has tried to exploit the antibody response in identification of antigens (diagnostic marker) which is responsible for the symptomatic VL cases. A prominent band recognized by active patient sera has been identified which in the course of treatment gradually fades-out and finally disappears or virtually disappear in six month follow up. This band was found absent in all other study groups except in few endemic healthy control subjects (6\%) indicating its potential as a marker of VL patients.

\section{Methodology}

\section{Parasites and crude soluble antigen (CSA)}

L. donovani parasites (MZP 151) drawn from splenic aspirates of sodium antimony gluconate (SAG) refractory VL patients from endemic region (Muzaffarpur, Bihar, India) were inoculated in biphasic medium in NNN tube. After 7 days of incubation the culture was grown at $25^{\circ} \mathrm{C}$ in RPMI-1640 medium (HyClone) supplemented with $0.2 \% \mathrm{NaHCO}_{3}, 2.05 \mathrm{mM}$
L-Glutamine, 12 mM HEPES buffer (HiMedia, India), $15 \%(\mathrm{v} / \mathrm{v})$ heat inactivated FBS (Gibco, Germany) and $50 \mathrm{mg} / \mathrm{l}$ Gentamycin and subculture at an average density of $5 \mathrm{X} 10^{7}$ cells $/ \mathrm{ml}$. Parasites of stationary phase were pelleted at $6000 \mathrm{rpm}$ for 20 minutes at $4^{\circ} \mathrm{C}$. Pellets were pooled and washed for 4 times in PBS and stored at $-70^{\circ}$. Approximately equal volume of the lysis buffer (7.4 pH, Tris HCl 20 mM, NaCl 40 mM, EDTA 10 mM, PMSF prepared in methanol $2 \mathrm{mM}$, leupeptine $10 \mu \mathrm{g} /$ ml, Nonidet-40 2\%, $10 \%$ SDS 0.4\% maintained in TDW) was added to the pellet and mixed thoroughly. The solution was then sonicated (Soniprep 150) at 12 amplitude for 10 cycles $30 \mathrm{sec}$. each in cold-chain. Further, the suspension was centrifuged at $3000 \mathrm{rpm}$ and $4^{\circ} \mathrm{C}$ for 20 minutes. The supernatant, crude soluble antigen (CSA). was collected and stored at $-70^{\circ} \mathrm{C}$ until use. The protein concentration in the CSA was quantified by dye binding method using albumin as the standard protein (Bradford 1976).

\section{Human sera}

Altogether 138 blood samples from different study subjects were collected for analysis of antibodies in the sera. Sera from 35 microscopically confirmed Kalaazar cases (Day-0), 14 post treated (Day-31) with complete course of amphotericin B deoxycholate (infusion of $1 \mathrm{mg} / \mathrm{kg}$ on alternate days for 1 month), 24 follow up (Day-180), and 33 healthy attendants of the patients from the endemic region who were either positive or negative to the rK39 strip test (EC) were collected from study site. For the non-endemic healthy control, blood samples from 13 volunteers were collected from Varanasi who had no history of kalaazar (NEHC). Samples from 19 patients of different diseases other than Kala-azar (DD) were collected from Sir Sundar Lal Hospital, BHU, Varanasi, which comprised malaria $(n=5)$, tuberculosis $(n=6)$, amoebic liver abscesses $(n=2)$, enteric fever $(n=4)$ and meningitis $(n=2)$. The sera were collected by centrifuging the blood samples at $3000 \mathrm{rpm}$ at room temperature for 5 minutes and were stored at $-70^{\circ} \mathrm{C}$ until use.

\section{Sodium dodecyle sulphate polyacrylamide gel electrophoresis (SDS-PAGE) and immunoblotting} SDS-PAGE was run as described by (Laemmli 1970). Briefly, a mixture of equal volume of CSA $(\sim 25 \mu \mathrm{g} / 5 \mathrm{~mm}$ well length) and sample buffer (Genei, Mumbai) was boiled for 5 minutes and loaded on to $12 \%$ polyacrylamide gel and electrophoresed at constant 
Krishna D. Manandhar/Identification of an antigenic.....

current of $25 \mathrm{~mA}$ for about 5 hour. Molecular weight markers (Fermentas) ranging from $11-170 \mathrm{kDa}$ were also run on both sides of the gel. Protein bands of CSA were visualized by staining with Comassie Brilliant Blue (CBB) $(0.025 \% \mathrm{w} / \mathrm{v}$ in $50 \%$ methanol and $10 \%$ acetic acid).

The immunoblotting of CSA was performed according to Towbin et al.1979 with some modifications. Briefly, the CSA ( 45 $\mu \mathrm{g} /$ well) in a broad well and prestained protein ladder to $5 \mathrm{~mm}$ well on both sides were electrophoresed in 12\% SDS PAGE. The fragmented proteins were then transferred to the polyvinylidene difluoride (PVDF) membrane $(0.45 \mu \mathrm{m}$ pore size, Millipore, USA) in transblotting unit (Amersham) containing transfer buffer (Tris base $25 \mathrm{mM}$, glycine $192 \mathrm{mM}$, methanol 5\%). The unit was run at constant voltage of $60 \mathrm{~V}$ for $2 \frac{1}{2} \mathrm{hr}$. The membrane was stained with $0.5 \%$ Ponceu red dye for five minutes and immediately destained after confirming the transfer of protein. The membrane was incubated in blocking buffer (1\% BSA, 0.1\% Tween-20 in PBS) overnight. The lane containing molecular weight markers were separated and the remaining membrane was cut into longitudinal strips of $5 \mathrm{~mm}$. These strips were incubated in sera (1:100 in PBS) of different study groups for 2 hours at room temperature. After washing (3 times15 minutes each) with washing buffer $(0.1 \%$ BSA, $0.1 \%$ Tween-20 in PBS), the strips were incubated with alkaline phosphatase enzyme conjugated goat antihuman IgG (1:1200) (Corredor Arjona.,et al.1999). Washing was repeated for thrice, twice with washing buffer and once with PBS. Colour was developed by using BCIP-NBT (5-Bromo-4-Chloro-3indolylphosphate + Nitro Blue Thiazole) as substrate (Promega, USA) until blue bands were appeared.

\section{Analysis}

The image of protein bands developed in SDS-PAGE and Western blot were captured and analysed the unknown molecular weight and average intergrated density value (AIDV) by using Alpha Imager ${ }^{\mathrm{TM}} 2200$.

\section{Results and Discussion}

Protein profile of $\boldsymbol{L}$. donovani: The CSA, which is a heterogenous mixture including both cytoplasmic and membrane bound component of virulent $L$. donovani promastigotes, run for SDS-PAGE expressed the protein profile of the parasites. The CSA from SAG resisted $L$. donovani showed about 32 prominent and many low intensified polypeptide bands ranging from $14-147 \mathrm{kDa}$ [Fig 1.]. The bands of 110, 100, 85, 74, 63, 59, 50, 44, 36, 31, 28, 22, 20 and $18 \mathrm{kDa}$ were found with high intensities as confirmed by AIDV.

Immunoblotting: The peptides bands appeared in the SDS-PAGE were later found to be transferred to PVDF membrane treated with sera of Day- 0 patients. The analysis of the Western blot profiles of different study

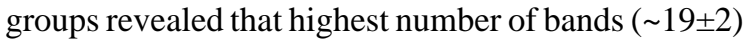
were present in the strips interacted by antibodies of Day-0 sera. The numbers of bands were found reduced by $30 \%(\sim 13 \pm 3)$ just after the completion of treatment in Day-31 group, however, the number appeared were not considerably less in the 6 month follow up ( 11 2 ).

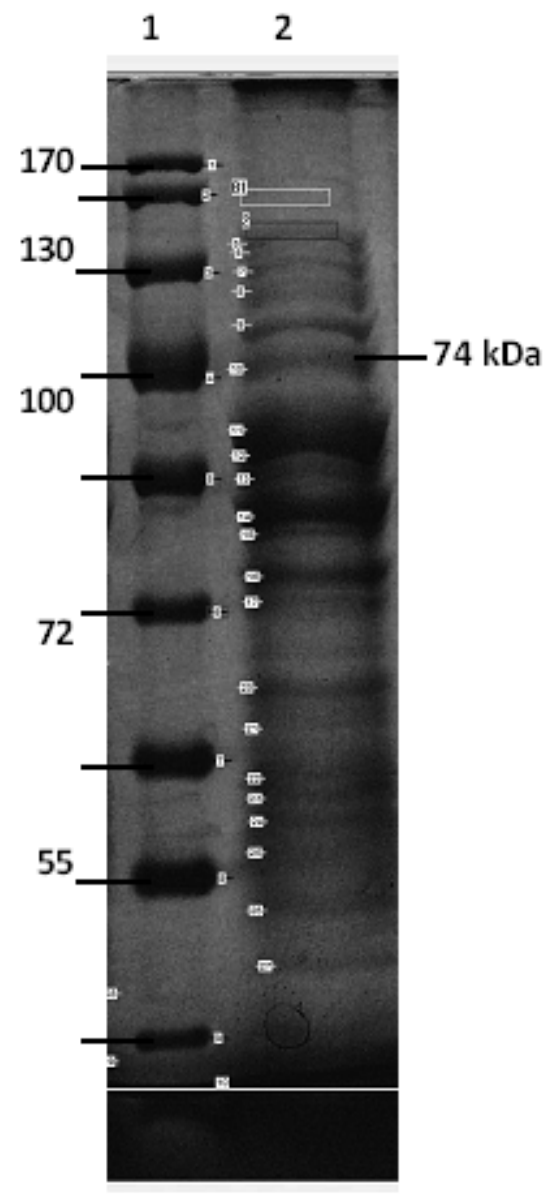

- Fig.l. CBB-stained SDS-PAGE gel. Lane 1, prestained mol wt. marker and lane 2 Leishmania antigen. 


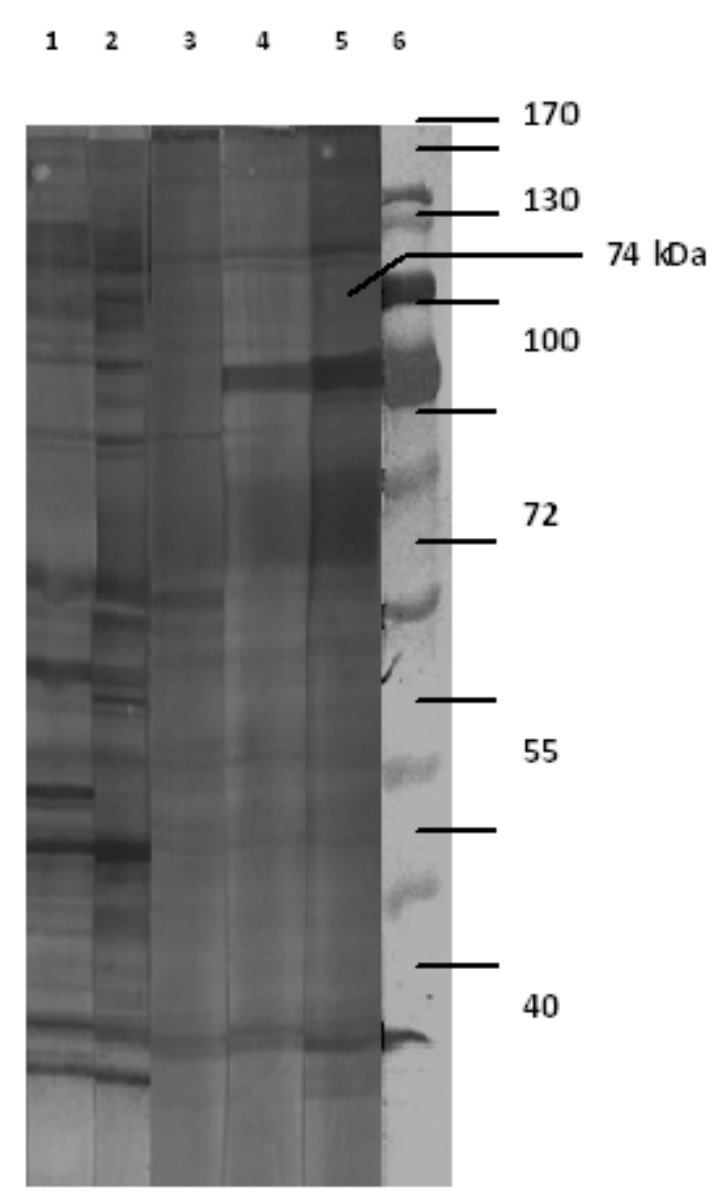

Fig. 3. Comparison of Western blot profiles; Lane 1, Nonendemic Healthy Control (NEHC); Lane 2,Endemic Control(EC); Lane 3, Patient after 6 month of successful treatment (Day-180); Lane 4, Patient after a month long complete treatment (Day-31); and Lane 5, Active Visceral leishmaniasis patient (VL); and Lane 6, prestained protein marker

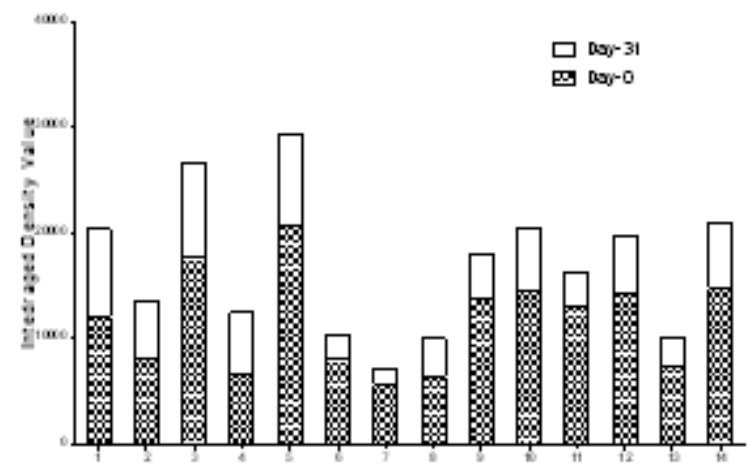

instringstis

Fig. 2. Comparative average integrated density values of 74 $\mathrm{kDa}$ band in immunoblot profiles of Day 0 and Day 31.
Additions to it, the intensities of the bands were also not reduced except in some. The other control groups had comparatively less number of average bands (d” 9). Most of the bands were not consistently appeared. Eighteen bands were found in more than $50 \%$ profiles of Day- 0 group and none of them were completely absent in all the profiles of Day-31 group. The patients of other disease group did not show cross reactivity to 74, 31, 28 and 16 kDa proteins (Table I).

$\mathbf{7 4}$ kDa Protein fraction: It was interesting to note that intensified $74 \mathrm{kDa}$ protein fraction was detected by the $100 \%$ sera of Day-0 and its intensity was found consistently low when interacted with sera of Day-31 [Fig 2]. The AIDV in Day 31 (5110 \pm 634$)$ was $45 \%$ less than in Day-0 (11385 \pm 1230$)$. Although, the band was present in $86 \%$ strips of Day-31 group, the intensity was decreased significantly ( $p$ value, $<0.0001$ ). The progressive decrease on intensity of the band was either vanished $(n=20)$ or very dimly recognized $(n=4)$ in Day-180 strips. This band was found only in virtually absent state of $6 \%$ strips of the EC group. Furthermore, it had neither shown cross-reactivity with NEHC nor any other non-Kalaazar disease group (Table 2).

Sensitivity, specificity and cross-reactivity of $\mathbf{7 4}$ kDa protein fraction: All the 35 sera of pretreated patients found interactive with the $74 \mathrm{kDa}$ protein fraction expressing its absolute sensitivity. It declined to $86 \%$ when interacted with sera collected just after completion of one month long treatment by amphotericin B deoxycholate to the patients. The sensitivity percentage further declined to 17 with sera from six-month follow up. Although the $17 \%$ sera samples $(n=4)$ showed interactive to the protein, they could be considered as negative on the basis of AIDV (Table 2).

All most all sera collected from the relatives inhabiting in close vicinity to patients who were expected to be exposed to sandfly vectors, did not show interaction with the $74 \mathrm{kDa}$ antigen and had $94 \%$ specificity in endemic region. However, the bands seen in 2 strips treated with sera from EC were dimly recognized. Therefore, if the bands were considered as negative, it will have $100 \%$ specificity. Precisely, it showed $100 \%$ specificity with sera collected from Varanasi, a non-endemic population. 
Krishna D. Manandhar/Identification of an antigenic.....

Table 1. Average number of bands and percentages of some notable major protein fractions developed in the immunoblot after interaction of protein profile of crude soluble antigen transferred to PVDF membrane with the sera of different study groups

\begin{tabular}{|c|c|c|c|c|c|c|}
\hline & $\begin{array}{c}\text { Day - } 0 \\
(n=35)\end{array}$ & $\begin{array}{c}\text { Day-31 } \\
(n=14)\end{array}$ & $\begin{array}{c}\text { Day-180 } \\
(n=24)\end{array}$ & $\begin{array}{c}\text { EC } \\
(n=33)\end{array}$ & $\begin{array}{l}\text { NEHC } \\
(\mathrm{n}=13)\end{array}$ & $\begin{array}{c}\text { DD } \\
(\mathrm{n}=19)\end{array}$ \\
\hline Average nos, of band seen in PVDF & 19 & 13 & 11 & 9 & 8 & 9 \\
\hline Std Dev & \pm 2.04 & \pm 3.18 & \pm 2.08 & \pm 8.73 & \pm 4.90 & \pm 2.78 \\
\hline Bands of interest (ADa) & \multicolumn{6}{|c|}{ Percentages of $b$ ands appeared } \\
\hline 120 & 74 & 71 & 82 & 52 & 38 & 53 \\
\hline 85 & 80 & 43 & 26 & 18 & 15 & 16 \\
\hline 74 & 100 & 86 & 17 & 9 & 0 & 0 \\
\hline 70 & 54 & 50 & 75 & 30 & 23 & 58 \\
\hline 63 & 86 & 14 & 60 & 9 & 0 & 11 \\
\hline 53 & 51 & 36 & 43 & 0 & 0 & 5 \\
\hline 51 & 71 & 36 & 43 & 12 & 54 & 5 \\
\hline $\mathbf{5 0}$ & 57 & 50 & 68 & 6 & 8 & 47 \\
\hline 37 & 57 & 64 & 81 & 61 & 15 & 26 \\
\hline 36 & 57 & 21 & 33 & 27 & 8 & 16 \\
\hline 34 & 54 & 50 & 54 & 24 & 62 & 42 \\
\hline 31 & 80 & 29 & 20 & 9 & 15 & 0 \\
\hline 28 & 80 & 79 & 66 & 42 & 23 & 0 \\
\hline 20 & 66 & 29 & 64 & 21 & 23 & 37 \\
\hline 18 & 51 & 21 & 50 & 18 & 0 & 5 \\
\hline 16 & 69 & 57 & 78 & 64 & 8 & 0 \\
\hline 14 & 63 & 36 & 22 & 12 & 0 & 11 \\
\hline
\end{tabular}

Moreover, the protein fraction did not interacted with antibodies of sera from patients of other diseases such as malaria, tuberculosis, amoebic enteric fever and meningitis. This result clearly approved its nil cross-reactivity with many common diseases (Table 1).

Parasitological method for diagnosis of VL is still the gold standard technique with $100 \%$ specificity. However, splenic smear remained failure to detect $18.4 \%$ of all cases who were benefited from VL therapy (Sundar et al. 2007). In many cases like in cutaneous and visceral leishmaniasis, the demonstration of parasite becomes very difficult in the aspirate samples and serodiagnosis becomes the alternative method for the purpose (Kar 1995, Zeyrek et al. 2007). Immunochromatographic strip test (rK39) is one of the valuable achievements in VL diagnostic array. There are some constraints in this tool, for instances, this strip remains many times failure to evaluate cure patients, relapse cases and discriminate the symptomatic and asymptomatic cases in endemic population (Boelaert et al. 2007). 
Table 2. Recognition of $74 \mathrm{kDa}$ protein fraction of L.donovani by human serum antibody of different study groups and analysis of sensitivity, specificity and cross-reactivity

\begin{tabular}{|c|c|c|c|}
\hline Study Group & No. of sanples & No. of positiveinegative & $\%$ \\
\hline \multicolumn{4}{|l|}{ Sensitivity } \\
\hline $\begin{array}{l}\text { Day-0 } \\
\text { Day-31 } \\
\text { Day-180 }\end{array}$ & $\begin{array}{l}35 \\
14 \\
24\end{array}$ & $\begin{array}{c}35 \\
12^{4} \\
4\end{array}$ & $\begin{array}{l}100 \\
86 \\
17\end{array}$ \\
\hline \multicolumn{4}{|l|}{ Specificity } \\
\hline $\begin{array}{l}\mathrm{EC} \\
\mathrm{NEHC}\end{array}$ & $\begin{array}{l}33 \\
13\end{array}$ & $\begin{array}{l}31^{4} \\
13\end{array}$ & $\begin{array}{c}94 \\
100\end{array}$ \\
\hline \multicolumn{4}{|l|}{ Cross-reactivity } \\
\hline $\begin{array}{l}\text { Malaria } \\
\text { Tuberc ulosis } \\
\text { Amoebic Liver Absceses } \\
\text { Enteric Fever } \\
\text { Meningitis }\end{array}$ & $\begin{array}{l}5 \\
6 \\
2 \\
4 \\
2\end{array}$ & $\begin{array}{l}0 \\
0 \\
0 \\
0 \\
0\end{array}$ & $\begin{array}{l}0 \\
0 \\
0 \\
0 \\
0\end{array}$ \\
\hline
\end{tabular}

Day-0, Pretreatment; Day-31, After completion of treatment of 31 days; Day-180, six month after the treatment; EC, Endemic Control Population; NEHC, Non Endemic Healthy Control Population.

${ }^{\text {a }}$ Confirmation of positive to confirmed patients; ${ }^{\text {b }}$ Confirmation of negative to non-VL cases; ${ }^{\mathrm{c}}$ Positive reactivity by non-VL ailments; ${ }^{\mathrm{d}}$ Positivity expressed by low intensified bands; ${ }^{\mathrm{e}}$ Virtually absent bands

In this study, we found 32 prominent peptide bands ranging from 14 to $147 \mathrm{kDa}$ from leishmanial crude soluble antigen of MZP151 in a SDS-PAGE stained with CBB (Fig 1.). In similar pattern, Afrin et al. (2002) reported 33 distinct polypeptides ranging in molecular mass from 18 to $153 \mathrm{kDa}$ and 17-20 bands of 14-66 kDa by Singh et al. (1995). The leishmanial proteins when transblotted to PVDF membrane [Fig. 2], 41 bands of different molecular mass in 35 profiles were appeared variably in Day-0 group due to the inconsistent antigen binding response of IgG class antibodies of the sera to $L$. donovani polypeptides. Thirty-six polypeptides, with molecular weights ranging from 14 to $123 \mathrm{kDa}$, were demonstrated by dos Santos et al. (1987). The blots obtained with patient sera revealed a broad range of immune specificities and extensive heterogeneity of the serological anti-LD responses in the individual patients (Forgber et al. 2006). It has also been known for decades that sera of all vertebrate taxa have natural anti-Leishmania antibodies (Rezai et al. 1975,
Ulrich et al. 1986). Therefore, disagreement to the report of Kumar et al. (2002), the reduction in number of bands after the treatment was not drastic but found in average of $19 \pm 2,13 \pm 3$ and $11 \pm 3$ in Day-0, Day-31 and Day-180 respectively. The reduction of bands would be useful tool to study the kinetics of recovery.

In contrast to $100 \%$ reactive $65 \mathrm{kDa}$ (Kumar et al. 2002), and 120, 91, 72, 63, 51, 34 and $31 \mathrm{kDa}$ (Ravindran et al. 2004) protein component of $L$. donovani, this study found only the $74 \mathrm{kDa}$ protein fraction against which consistent antibodies were developed. In the case of L. d. infantum $100 \%$ reactivity was reported with 94 kDa polypeptide (Rolland et al. 1994). The antibody responses to the parasites show highly individuality (Forgber et al. 2006) which could be the reason for dissimilar result.

In this study, some bands including $74 \mathrm{kDa}$ fraction appeared in Day-0 group were waned out after completion of treatment. It is due to the fall of the level 
Krishna D. Manandhar/Identification of an antigenic.....

of circulating immune complexes after treatment as analysed by antigen specific ELISA (Srivastava 1989). Similarly, the decreases of titer level of the antibodies in cured patient than in the active VL patients have been reported by Kumar et al. (2002) and Atta et al. (2004), and negativity ranged to $50 \%$ and $89 \%$ after treatment up to 1 year and 2-8 year respectively according to Hailu (1990). The drug pressure might also have suppressed most of the antibodies against the Leishmanial antigens (Khan et al. 1998). The disappearance or virtually disappeared band of $74 \mathrm{kDa}$ protein fraction is directly proportionate to recovery from disease, suggesting no more antibodies are being developed against the fraction of the protein due to destruction of the same. Hence, it can be concluded that the $74 \mathrm{kDa}$ protein fraction is playing role in conversion to symptomatic subjects.

Serologically, cross-reactivity between Leishmania species and other pathogens has been reported for whole-cell lysates (Smrkovski and Larson 1977, dos Santos et al. 1987). Molecular weights 72, 56, 50, and 40 $\mathrm{kDa}$ were found to be cross reactive with sera of patients of other diseases (Tiwari et al. 1995). In this study 125, $120,107,70,38$, and $30 \mathrm{kDa}$ showed the cross-reactivity in $>50 \%$ of strips which expressed their meaningless role in diagnosis of VL. But 16, 28, 31 and $74 \mathrm{kDa}$ protein fractions did not show any cross-reactivity to the other diseases. However, the $74 \mathrm{kDa}$ became the only one which was also not reacted with sera of NEHC and least with EC. Furthermore, though, the dim band was appeared in the EC population, it was virtually absent indicating its potential as a diagnostic marker in Indian population. In Spanish population 14 and/or $16 \mathrm{kDa}$ proteins were reported as diagnostic marker (Riera et al. 2004, GarciaGarcia et al. 2006) for the active VL patients.

There is great lack of diagnostic tool for this neglected tropical disease which is able to avoid false positivity in the endemic population and successfully treated patients. The very popular field friendly, rK39 strip test, though has absolute sensitivity and specificity, it is non predictable to cured patients as it still shows positive result after successful treatment and even after six-month follow up cases (Singh et al. 2009). Similarly, in the endemic population it missed to predict 3\% endemic population and $14.3 \%$ non cases as negative (Sundar et. al. 2007). In this research work, $74 \mathrm{kDa}$ protein was found able to evaluate the buffer population promptly by Western blot technique with its $100 \%$ sensitivity, and $100 \%$ and $94 \%$ specificity in NEHC and EC population respectively (Table 1).

Though, $74 \mathrm{kDa}$ protein was previously reported from L. donovani (C-II strain) (Khan et al. 1998), Indian PKDL as 72-74 (Singh et al. 2003) and American VL (Evans et al. 1989), so far in our knowledge, this is the first time to report it with high potential diagnostic marker. This fraction of the protein was found highly conserved in SAG resistant strain of L. donovani from endemic area. Its intensity found to be decreased by $45 \%$ just after treatment, absent in all cases of NEHC and non-Kala-azar disease group, and virtually absent in EC. These pictures clearly demonstrate that $74 \mathrm{kDa}$ protein fraction of L. donovani could be a biological marker of Indian Kala-azar which is being in search for a long time. Furthermore, the gradual significant decrease $(p=0.0001)$ of band intensities of in the course of treatment are an additional usefulness of $74 \mathrm{kDa}$ protein fraction for prognosis and kinetic study of recovery from Kala-azar.

\section{Acknowledgements}

I am grateful to the Prof. Shyam Sundar and research scholars of Infectious Diseases Research Laboratory, BHU for providing all necessary laboratory facilities and Kala-azar Medical Research Centre team, Muzaffarpur, India, for providing parasite sample. Special thanks to UGC, Nepal for providing a fellowship for this research work.

\section{References}

Afrin, F., R. Rajesh et al. 2002. Characterization of Leishmania donovani antigens encapsulated in liposomes that induce protective immunity in BALB/C mice. Infect Immun. 70(12):6697-6706.

Aisa, M.J., S. Castillejo et al. 1998.Diagnostic potential of Western blot analysis of sera from dogs with leishmaniasis in endemic areas and significance of the pattern. Am J Trop Med Hyg. 58(2):154-159.

Albertini, M., I. Leger et al. 1993. Severe visceral leishmaniasis with hepatic involvement. Diagnostic value of the immunoblotting serologic technic]. Pediatrie. 48(5):377-380.

Ashford, R.W., P. Desjeux et al. 1992. Estimation of population at risk of infection and number of cases of Leishmaniasis. Parasitol. Today. 8(3):104-105.

Atta, A.M., R. Colossi et al. 2004. Antileishmanial IgG and IgE antibodies recognize predominantly carbohydrate 
epitopes of glycosylated antigens in visceral leishmaniasis. Mem Inst Oswaldo Cruz. 99(5):525-530.

Badaro, R., D. Benson et al. 1996. rK39: a cloned antigen of Leishmania chagasi that predicts active visceral leishmaniasis. J Infect Dis. 173(3):758-761.

Berman, J.D. 1997. Human leishmaniasis: clinical, diagnostic, and chemotherapeutic developments in the last 10 years. Clin Infect Dis. 24(4):684-703.

Boelaert, M., S. Bhattacharya et al. 2007. Evaluation of rapid diagnostic tests: visceral leishmaniasis. Nature Publishing Group. 530-539.

Bradford, M. M. 1976. A rapid and sensitive method for the quantitation of microgram quantities of protein utilizing the principle of protein-dye binding. Anal Biochem. 72:248-254.

Corredor Arjona, A., C. A.Alvarez Moreno et. al. 1999. Prevalence of Trypanosoma cruzi and Leishmania chagasi infection and risk factors in a Colombian indigenous population. Rev Inst Med Trop Sao Paulo. 41(4): 229-234.

Da Costa, J.M., A.B. Neogy et al. 1996. Antigenic components of partially purified antigens of Leishmania donovani infantum recognized by sera from dogs with asymptomatic or active visceral leishmaniasis. Am J Trop Med Hyg. 55(5):511-515.

Desjeux, P. 2004. Leishmaniasis: current situation and new perspectives. Comp Immunol Microbiol Infect Dis. 27(5):305-318.

dos Santos, J. I., M. G.Morgado et al. 1987. Human visceral leishmaniasis: analysis of the specificity of humoral immune response to polypeptides of Leishmania donovani chagasi. Am J Trop Med Hyg. 37(2):263-270.

Evans, T. G., E. C. Krug et al. 1989. Evaluation of antibody responses in American visceral leishmaniasis by ELISA and immunoblot. Mem Inst Oswaldo Cruz. 84(2):157166.

Fernandez-Perez, F. J., S. Mendez et al. 1999. Value of Western blotting in the clinical follow-up of canine leishmaniasis. J Vet Diagn Invest. 11(2):170-173.

Forgber, M., R. Basu et al. 2006. Mapping the antigenicity of the parasites in Leishmania donovani infection by proteome serology. PLOS ONE. 1: e40.

Garcia-Garcia, J. A., J. Martin-Sanchez et al. 2006. Use of noninvasive markers to detect Leishmania infection in asymptomatic human immunodeficiency virus-infected patients. J Clin Microbiol. 44(12):4455-4458.

Ghose, A.C., J.P. Haldar et al. 1980. Serological investigations on Indian kala-azar. Clin Exp Immunol. 40(2):318-326.

Hailu, A. et. al. 1990. Pre- and post-treatment antibody levels in visceral leishmaniasis. Trans $R$ Soc Trop Med Hyg. 84(5):673-675.

Handman, E., H. M. Jarvis et al. 1984. Leishmania major: identification of stage-specific antigens and antigens shared by promastigotes and amastigotes. Parasite Immunol. 6(3):223-233.
Ilg, T., D. Craik et al. 1998. Stage-specific proteophosphoglycan from Leishmania mexicana amastigotes. Structural characterization of novel mono-, di-, and triphosphorylated phosphodiester-linked oligosaccharides. J Biol Chem. 273(22):13509-13523, 1998.

Kar, K. et al. 1995. Serodiagnosis of leishmaniasis. Crit Rev Microbiol. 21(2):123-152.

Khan, N. B., A. Ali et al. 1998. Immunoblot Analysis of Antigens of Promastigotes (C-II Strain) of Leishmania with Human Patient Sera. J Parasit Appl Anim Bio. 7(1):718.

Kumar, P., K. Pai et al. 2002. Immunoblot analysis of the humoral immune response to Leishmania donovani polypeptides in cases of human visceral leishmaniasis: its usefulness in prognosis. Clin Diagn Lab Immunol. 9(5):1119-1123.

Laemmli, U. K.1992. Cleavage of structural proteins during the assembly of the head of bacteriophage T4. Nature 227(5259):680-685.

Manuel, J. and R. Behin. 1987. The leishmaniasis in biology and medicine. Eds. W Peters \& R Killick-Kendrick. Academic Press, London. Pp 731.

Mary, C., D. Lamouroux et al. 1992. Western blot analysis of antibodies to Leishmania infantum antigens: potential of the 14-kD and 16-kD antigens for diagnosis and epidemiologic purposes. Am J Trop Med Hyg. 47(6):764-771.

Mengeling, B. J., S. M. Beverley et al. 1997. Designing glycoconjugate biosynthesis for an insidious intent: phosphoglycan assembly in Leishmania parasites. Glycobiology 7(7):873-880.

Piani, A., T. Ilg et al. 1999. Leishmania major proteophosphoglycan is expressed by amastigotes and has an immunomodulatory effect on macrophage function. Microbes Infect. 1(8):589-599.

Pun, SB., T. Sato et al. 2011. Changing trends in visceral leishmaniasis: 10 years' experience at a referral hospital in Nepal. Transactions of the Royal Society of Tropical Medicine and Hygiene 105(10):550-554

Rami, M., T. Atarhouch et al. 2005. Identification of two highly performing Leishmania infantum antigens for serodiagnosis of canine leishmaniosis. Vet Parasitol. 134(1-2):25-31.

Ravindran, R., K. Anam et al. 2004. Characterization of immunoglobulin $\mathrm{G}$ and its subclass response to Indian kala-azar infection before and after chemotherapy. Infect Immun. 72(2):863-870.

Rezai, H.R., S. Ardehali et al. 1975. Anti-leishmania activity of normal animal sera. Ann Trop Med Parasitol. 69(1):29-33.

Riera, C., R. Fisa et al. 2004. Detection of Leishmania infantum cryptic infection in asymptomatic blood donors living in an endemic area (Eivissa, Balearic Islands, Spain) by different diagnostic methods. Trans R Soc Trop Med Hyg. 98(2):102-110. 
Krishna D. Manandhar/Identification of an antigenic.....

Rolland, L., V. Zilberfarb et al. 1994. Identification of a 94kilodalton antigen on Leishmania promastigote forms and its specific recognition in human and canine visceral leishmaniasis. Parasite Immunol. 16(11):599-608.

Salotra, P., A. Raina et al. 1999. Immunoblot analysis of the antibody response to antigens of Leishmania donovani in Indian kala-azar. Br J Biomed Sci. 56(4):263-267.

Singh, N., S. Nagar et al. 1995. Antigenic Aanalysis of soluble fraction of Leishmania donovani by SDS -PAGE and Immunoblotting. Indian J Exp Biol. 33:313-315.

Singh, D.P., S. Sundar et al. 2009. The rK39 strip test is nonpredictor of clinical status for kala-azar. BMC Research Notes, 2:187

Singh, S. and R. Sivakumar. 2003. Recent advances in the diagnosis of leishmaniasis. J Postgrad Med. 49(1):55-60.

Smrkovski, L. L. and C.L. Larson. 1977. Antigenic crossreactivity between Mycobacterium bovis (BCG) and Leishmania donovani. Infect Immun. 18(2):561-562.

Srivastava, L. 1989. Comparative evaluation of serological tests in diagnosis of kala azar. Indian J Med Res. 89:265270

Stierhof, Y. D., P.A. Bates et. al. 1999. Filamentous proteophosphoglycan secreted by Leishmania promastigotes forms gel-like three-dimensional networks that obstruct the digestive tract of infected sandfly vectors. Eur J Cell Biol. 78(10): 675-689.
Sundar, S., R.K. Singh et al. 2007. Comparative evaluation of parasitology and serological tests in the diagnosis of visceral leishmaniasis in India: a phase III diagnostic accuracy study. Trop Med Int Health. 12(2): 284289.

Tiwari, V., A. Jain et. al. 1995. Evaluation of antibody responses in Indian kala-azar by immunoblot. Biochem Mol Biol Int. 37(5): 959-964.

Towbin, H., T. Staehelin et al. 1979. Electrophoretic transfer of proteins from polyacrylamide gels to nitrocellulose sheets: procedure and some applications. Proc Natl Acad Sci U S A. 76(9):43504354.

Ulrich, M., M. Centeno et al. 1986. Serotypes of Leishmania mexicana and $\mathrm{L}$. braziliensis defined by enriched polyclonal sera, with particular reference to Venezuelan isolates. Acta Cient Venez. 37(5):591-592.

Yao, C., Y. Chen et al. 2008. Leishmania chagasi: Homogenous metacyclic promastigotes isolated by buoyant density are highly virulent in a mouse model. Exp Parasitol.118(1):129-133

Zeyrek, F. Y., M. Korkmaz et. al. 2007. Serodiagnosis of anthroponotic cutaneous leishmaniasis (ACL) caused by Leishmania tropica in Sanliurfa Province, Turkey, where ACL Is highly endemic. Clin Vaccine Immunol. 14(11):1409-1415. 
Nepal Journal of Science and Technology Vol. 13, No. 2 (2012) 63-72 